\title{
Determination of Immune Memory to Hepatitis B Vaccination Through Early Booster Response in College Students
}

\author{
Chyi-Feng Jan, ${ }^{1,2}$ Kuo-Chin Huang, ${ }^{1}$ Yin-Chu Chien, ${ }^{3}$ Donald E. Greydanus, ${ }^{2}$ H. Dele Davies, ${ }^{2}$ Tai-Yuan Chiu, ${ }^{1}$ \\ Li-Min Huang, ${ }^{4}$ Chien-Jen Chen, ${ }^{2,5}$ and Ding-Shinn Chen ${ }^{6}$
}

The long-term protection of hepatitis $B$ (HB) vaccination has been debated for years. The purpose here was to evaluate the kinetic changes of antibody to $\mathrm{HB}$ surface antigen (anti$\mathrm{HBs}$ ) and define immune memory of the $\mathrm{HB}$ vaccine among college students who had previously received full neonatal immunization against HB. In all, 127 college students aged 1823 years born after July 1984 who had completed $\mathrm{HB}$ vaccination and were seronegative for all three $\mathrm{HB}$ viral markers, including $\mathrm{HB}$ surface antigen $(\mathrm{HBs} \mathrm{Ag})$, antibody to $\mathrm{HB}$ core protein (anti-HBc), and anti-HBs, were recruited. They received three doses of $\mathrm{HB}$ vaccine at enrollment, 1 month and 6 months after enrollment. Their anti-HBs titers were assayed at enrollment, 7-10 days, 1 month, 6 months, and 7 months following the first dose of HB vaccine. The anti-HBs seroprotective rates for subjects 7-10 days, 1 month, 6 months, and 7 months postvaccination were $20.5 \%, 75.6 \%, 94.5 \%$, and $99.2 \%$, respectively. Those who were seroprotective at 7 to 10 days after one dose of $\mathrm{HB}$ vaccine booster developed significantly higher levels of anti-HBs at 1 and 6 months than those not developing seroprotective anti-HBs response at an earlier timepoint. Conclusion: At least one-quarter of HB vaccinees have lost their immune memory to the $\mathrm{HB}$ vaccine when entering college. Immune memory to $\mathrm{HB}$ vaccine was identified by early seroconversion, which was present in only $20 \%$ of vaccinees in the present study. To ensure higher than $90 \%$ anti-HBs seroconversion rates, at least 2 doses of $\mathrm{HB}$ booster vaccines are recommended for at-risk youths who received complete $\mathrm{HB}$ vaccinations in neonatal or infant periods but are seronegative for $\mathrm{HBsAg}$, antiHBs, and anti-HBc in adolescence. (HePATOLOGY 2010;51:1547-1554)

\section{See Editorial on Page 1485.}

U niversal hepatitis B (HB) immunization has been implemented for more than 20 years in Taiwan and led to remarkable reductions in acute and chronic liver diseases. ${ }^{1,2}$

The national immunization program of Taiwan was launched in 1984: all neonates or infants born before
Nov 1992 received plasma-derived HB vaccines at birth. They all received standard doses of $\mathrm{HB}$ vaccines at birth according to the same standard protocol. The coverage rate of $\mathrm{HB}$ vaccines during the past 2 decades in Taiwan has been $>90 \%$ and data show that the national vaccine coverage rates were more than $95 \%$ in 2001 and 2002., It has shown an efficacy of $78 \%-87 \%$ in decreasing the seroprevalence of hepatitis B surface antigen (HBsAg)

Abbreviations: anti-HBc, antibody to hepatitis B core protein; anti-HBs, antibody to hepatitis B surface antigen; BMI, body mass index; GMT, geometric mean titers; $H B$, hepatitis $B$; $H B s A g$, hepatitis B surface antigen.

From the ${ }^{1}$ Department of Family Medicine, National Taiwan University Hospital, National Taiwan University, Taiwan; ${ }^{2}$ Pediatrics and Human Development, College of Human Medicine, Michigan State University, East Lansing, MI; ${ }^{3}$ Genomic Research Center, Academia Sinica, Taiwan; ${ }^{4}$ Department of Pediatrics, National Taiwan University Hospital, National Taiwan University, Taiwan; ${ }^{5}$ Graduate Institute of Epidemiology, College of Public Health, National Taiwan University, Taiwan; and

${ }^{6}$ Department of Internal Medicine and Graduate Institute of Clinical Medicine, National Taiwan University Hospital, National Taiwan University, Taiwan.

Received August 28, 2009; accepted January 3, 2010.

Supported by the Taiwan National Science Council (NSC 96-2314-B-002-115).

Address reprint requests to: Li-Min Huang, 7 Chung-Shan South Road, Taipei 100, Taiwan; Department of Pediatrics, National Taiwan University Hospital, National Taiwan University, Taipei, Taiwan. E-mail: Imhuang@ntu.edu.tw; fax: 886-2-23147450.

Copyright (C 2010 by the American Association for the Study of Liver Diseases.

Published online in Wiley InterScience (www.interscience.wiley.com).

DOI 10.1002/hep.23543

Potential conflict of interest: Dr. Huang is a consultant for and received grants from GlaxoSmithKline. 
carriage in all children, ${ }^{5,6}$ a $75 \%$ decrease in the incidence of hepatocellular carcinoma among children 6-9 years of age, ${ }^{1}$ and a $68 \%$ decline in mortality from fulminant hepatitis and HB-related liver diseases in infants. ${ }^{2}$

Although this national vaccination program has been very successful, a gradual yearly decline in antibody titers against the $\mathrm{HBsAg}$ among vaccinees was noted in several follow-up studies. ${ }^{7-11}$ The antibody to HBsAg (anti-HBs) seropositivity rate of the vaccinees decreased from $99 \%$ at 1 year to $83 \%$ at 5 years, $71.1 \%$ at 7 years, $37.4 \%$ at 12 years, and $37 \%$ at $15-$ 17 years. The seronegative rate for three $\mathrm{HB}$ viral markers including $\mathrm{HBs} \mathrm{Ag}$, antibodies to $\mathrm{HB}$ core protein (anti-HBc), and anti-HBs increased from 12.7\% at 1 year to $62.6 \%$ at $15-17$ years. Despite the effectiveness of $\mathrm{HB}$ immunization, natural $\mathrm{HB}$ infections were seen by detecting anti-HBc in $4.0 \%-5.7 \%$ of vaccine recipients in many studies. ${ }^{6,10,12}$ Case reports of vaccine failure have also been noted. ${ }^{13}$ The causes of failure may be lower vaccination coverage and incomplete $\mathrm{HB}$ immunization in the early era of the nationwide $\mathrm{HB}$ immunization program or poor response to HB immunization, including vaccine failure. ${ }^{14,15}$

Regarding immune memory to hepatitis $\mathrm{B}$ vaccination, $\mathrm{Lu}$ et al. $^{16}$ found that breakthrough infections might occur 10 to 15 years later for children who initially had a low response to the $\mathrm{HB}$ vaccine. One or more booster immunizations are needed in seronegative subjects 15 years after neonatal immunization with the plasma-derived $\mathrm{HB}$ vaccine. A recent study estimated that as high as $26.5 \%$ of fully vaccinated adolescents aged 15-18 years may have become immunologically naïve to the $\mathrm{HB}$ vaccine, raising concerns about the need for a booster vaccine for high-risk groups in the long run. ${ }^{7}$ An Alaskan study found that among children and adolescents vaccinated with $\mathrm{HB}$ vaccines during infancy there was an increased proportion of nonresponders among older adolescents, which may indicate waning immune memory. ${ }^{17}$

At the time of the present study the necessity for booster vaccinations for the prevention of $\mathrm{HB} 15$ years postvaccination in the group of young adults who have become seronegative for $\mathrm{HB}$ viral markers after complete neonatal $\mathrm{HB}$ vaccination was still under debate. Because an increased risk of $\mathrm{HB}$ infection is anticipated when adolescents enter into young adulthood through becoming sexually active, breakthrough infections such as fulminant $\mathrm{HB}$ might be the main concern instead of the risk of chronic $\mathrm{HB}$ carriage. To address this issue, we conducted this study to measure the booster responses after $\mathrm{HB}$ vaccination in seronegative young adults who had completed neonatal $\mathrm{HB}$ vaccines in Taiwan before. Moreover, we also tried to define immune memory to hepatitis $\mathrm{B}$ vaccination through early booster response in college students from this study.

\section{Subjects and Methods}

Study Population. This cohort study was conducted between October 2007 and January 2009. The target population was subjects aged 18-23 years who were born after 1984 when the Taiwanese national HB vaccination program was launched. All subjects in this study were born before 1992. Therefore, all the study subjects received the same plasma-derived $\mathrm{HB}$ vaccines and completed $\mathrm{HB}$ vaccination during infancy. Their vaccination records must have shown a completed neonatal $\mathrm{HB}$ vaccination, and they were seronegative for all three $\mathrm{HB}$ viral markers, including $\mathrm{HBsAg}$, anti-HBc, and anti-HBs within 2 years of entry into the study and at study entry. They were recruited through a Student's Health Center Clinic referral, Bulletin Board System posts, and Web-broadcast invitation. The neonatal HB vaccination records were verified through linkage to the Taiwan Center for Disease Control databank. Signed informed consent was obtained from all the participants and their parents or guardians. Pregnant females, persons with a previous history of allergy to $\mathrm{HB}$ vaccines, or allergy to yeast were excluded.

Protocol. All participants were tested for HB viral markers at enrollment, even if they had been tested in the previous months, to confirm their serostatus. A questionnaire was completed at enrollment to record sociodemographic factors including age, gender, selfreported family history of $\mathrm{HB}$ carriers, self-reported blood type, and so on. The participants then received three intramuscular doses of $\mathrm{HB}$ vaccine (Engerix-B, recombinant hepatitis B surface antigen, $20 \mu \mathrm{g} / \mathrm{mL} / \mathrm{vial}$, GlaxoSmithKline, Belgium) at baseline and at the first and sixth months follow-up visits. Their anti-HBs status was checked at baseline, 7-10 days, 1 month, 6 months, and 7 months following the first dose of $\mathrm{HB}$ vaccine. Adverse effects associated with the vaccine were also reported within 1 week after each Engerix-B injection.

Body mass index (BMI) cutoffs were adopted as suggested by the Department of Health in Taiwan including slim (BMI <18.5), normal $(18.5 \leq$ BMI $<24$ ), overweight and obese (BMI $\geq 24$ ) categories. This study was approved by the Ethic Review Committee of the National Taiwan University Hospital (Fig. 1). The primary endpoint of this study was to understand the kinetic changes of anti-HBs. Study subjects were categorized into three groups. Group A 


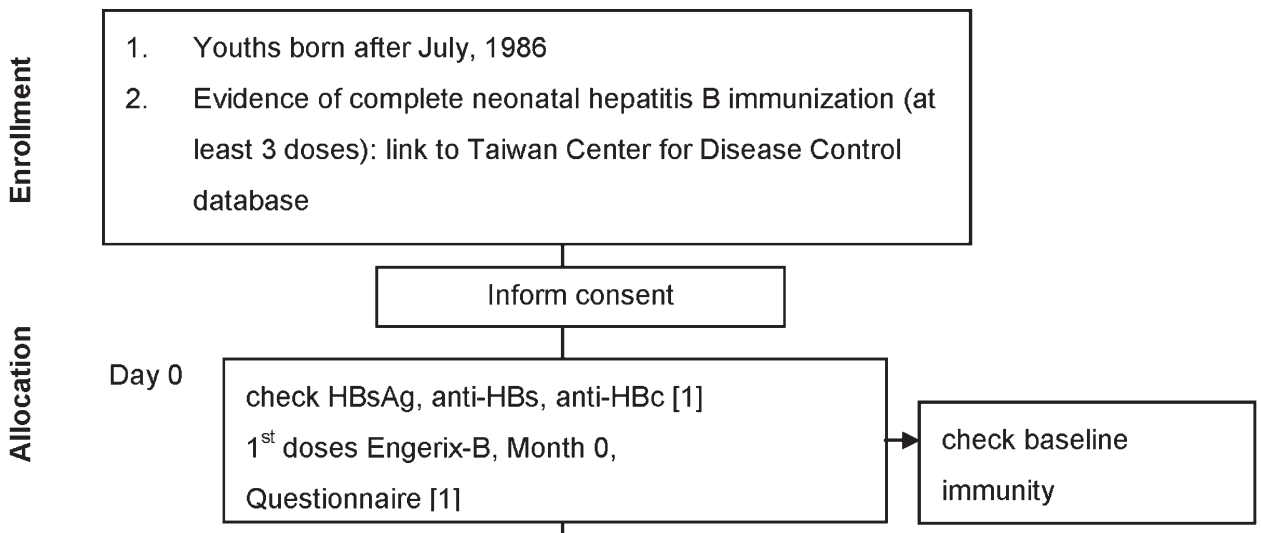

Fig. 1. Study flow chart.

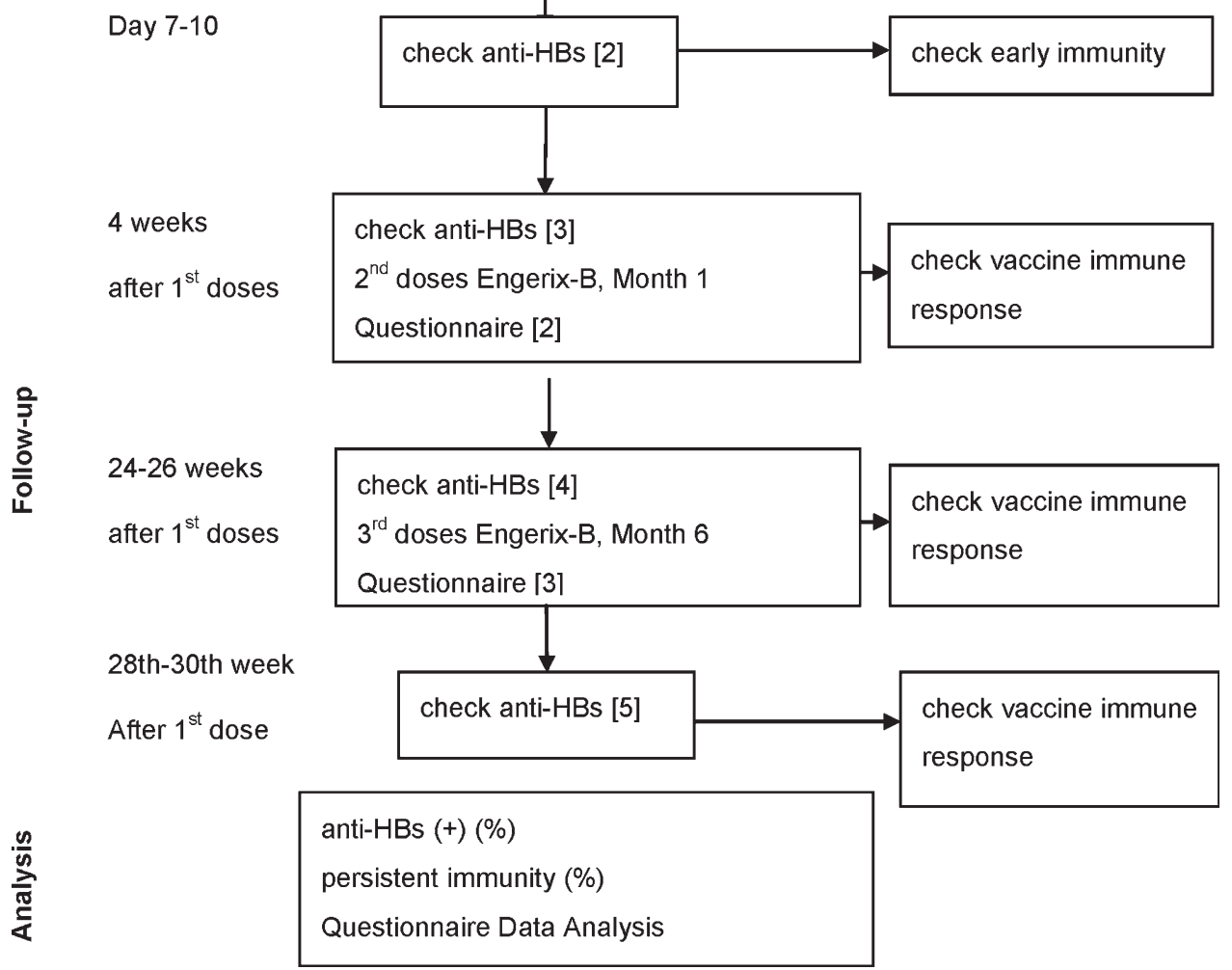

consisted of those who had anti-HBs $<10 \mathrm{mIU} / \mathrm{mL} 7$ 10 days after 1 dose of $\mathrm{HB}$ vaccination, whereas those with anti-HBs between $10-100 \mathrm{mIU} / \mathrm{mL}$ were in group $\mathrm{B}$ and those with anti-HBs between $\geq 100$ $\mathrm{mIU} / \mathrm{mL}$ were in group C.

Serum HB Viral Markers and Biochemistry. Seromarkers including $\mathrm{HBsAg}$, anti-HBc, and anti-HBs concentrations were determined using enzyme immunoassay kits (HBsAg and anti-HBs by Abbott; anti$\mathrm{HBc}$ by Roche Diagnostics). An anti-HBs titer $\geq 10$ $\mathrm{mIU} / \mathrm{mL}$ was considered seroprotective and titers between 10-100 $\mathrm{mIU} / \mathrm{mL}$ were considered low. The presence of immune memory to $\mathrm{HB}$ was defined as a negative prebooster anti-HBs $(<10 \mathrm{mIU} / \mathrm{mL})$ followed by a seroprotective titer $(\geq 10 \mathrm{mIU} / \mathrm{mL})$ at $7-10$ days after one dose of $\mathrm{HB}$ vaccine booster. When calculat- ing the geometric mean titers (GMT), a titer of 0.1 $\mathrm{mIU} / \mathrm{mL}$ was used for those lower than $0.1 \mathrm{mIU} / \mathrm{mL}$ and of $1,000 \mathrm{mIU} / \mathrm{mL}$ for those higher than 1,000 $\mathrm{mIU} / \mathrm{mL}$.

Sample Size. The sample size calculation conservatively assumed a $10 \%$ placebo response of participants had they not received the actual vaccine. The calculated group sample size necessary to have $90 \%$ power to detect a $20 \%$ early booster response with actual vaccine $(P<0.05$, two-tailed $)$ yielded a sample size of 120 . We chose to enroll 150 to allow a $20 \%$ dropout rate.

Statistical Analysis. Excel and SAS v. 9.1.3 were used for statistical analysis. Chi-square analysis and Fischer's exact test were used for comparing group proportions between seropositive and seronegative participants. GMT and their 95\% confidence intervals were 
Table 1. Characteristics of 126 Participants by Hepatitis B Surface Antibody (anti-HBs) Status

\begin{tabular}{|c|c|c|c|c|c|c|}
\hline Anti-HBs Status & & Day $7-10(+)$ & $\begin{array}{c}\text { Day 7-10(-) } \\
\text { and Month } 1(+)\end{array}$ & $\begin{array}{l}\text { Month } 1(-) \text { and } \\
\text { Month } 6(+)\end{array}$ & $\begin{array}{l}\text { Month } 6(-) \text { and } \\
\text { Month } 7(+)\end{array}$ & $P$ Value \\
\hline No. cases & & 26 & 70 & 24 & 6 & \\
\hline \multirow[t]{2}{*}{ Age (years) } & $<20$ & 9 & 33 & 9 & 2 & 0.669 \\
\hline & $\geq 20$ & 17 & 37 & 15 & 4 & \\
\hline \multirow[t]{2}{*}{ Sex } & Female & 11 & 36 & 11 & 3 & 0.888 \\
\hline & Male & 15 & 34 & 13 & 3 & \\
\hline \multirow[t]{3}{*}{ Family history of hepatitis B carrier } & Yes & 3 & 10 & 4 & 1 & 0.795 \\
\hline & No & 16 & 40 & 10 & 4 & \\
\hline & Unknown & 7 & 20 & 10 & 1 & \\
\hline \multirow[t]{5}{*}{ Blood type } & A & 7 & 15 & 5 & 0 & 0.319 \\
\hline & B & 5 & 16 & 7 & 3 & \\
\hline & $A B$ & 0 & 8 & 0 & 0 & \\
\hline & 0 & 13 & 26 & 12 & 2 & \\
\hline & Unknown & 1 & 5 & 0 & 1 & \\
\hline \multirow[t]{3}{*}{ Body mass index $\left(\mathrm{BMl}, \mathrm{kg} / \mathrm{m}^{2}\right)$} & $<18.5$ & 5 & 13 & 2 & 1 & 0.489 \\
\hline & $18.5 \sim 24$ & 17 & 53 & 20 & 4 & \\
\hline & $\geq 24$ & 4 & 4 & 2 & 1 & \\
\hline
\end{tabular}

also calculated using software developed by T.W. Kirkman. ${ }^{18}$ An analysis of variance (ANOVA) test was performed to compare the difference of the three groups at 1,6 , and 7 months categorized by the anti-HBs titers at 7-10 days after the booster. Statistical significance was set at $5 \%$.

\section{Results}

Initially, 150 seronegative subjects for the three hepatitis B viral markers (HBsAg, anti-HBs, and anti$\mathrm{HBc}$ ) were invited to participate in the study. Among them, five subjects were excluded because of seropositive results upon recheck or dropout. A history of complete neonatal $\mathrm{HB}$ vaccination could not be confirmed in 18 cases. Therefore, the remaining 127 cases entered the study to receive $\mathrm{HB}$ immunization. There were slightly more male than female participants. The mean age was $19.85 \pm 1.06$ years. No serious adverse effects were reported following the vaccinations.

After three doses of $\mathrm{HB}$ booster vaccines, only one person remained seronegative for anti-HBs. Table 1 shows the characteristics of the 126 participants who were seroprotective for anti-HBs after 7 months by their different response times. There were no significant differences in anti-HBs titers during the four follow-up periods with respect to the demographic or biophysical factors studied. Of note was that none of the participants (0/8) with blood type $A B$ had an early response following one dose of $\mathrm{HB}$ vaccine.

The seroprotective rates of anti-HBs for subjects 710 days, 1 month, 6 months, and 7 months after receiving their first dose of $\mathrm{HB}$ vaccine were $20.5 \%$, $75.6 \%, 94.5 \%$, and $99.2 \%$, respectively. No gender difference was noted in the anti-HBs level (Fig. 2).
There was no statistical difference found between the response and age either. The anti-HBs titer responses among participants with regard to different time periods are shown in Table 2. The anti-HBs titer response was highest at 7 months, followed by 6 months, 1 month, and then 7 to 10 days.

One month after the first dose of $\mathrm{HB}$ vaccine, $24.4 \%$ of participants had titers $<10 \mathrm{mIU} / \mathrm{mL}$ and $75.6 \%$ were seropositive, but $29.1 \%$ had low titers $(<100 \mathrm{mIU} / \mathrm{mL})$. Traditionally, the $24.4 \%$ subjects with anti-HBs $<10 \mathrm{mIU} / \mathrm{mL}$ would be regarded as having lost $\mathrm{HB}$ immune memory. However, the clinical significance of those with low seroprotective titers was less clear. They might have mounted a booster response based on existing immune memory. On the other hand, they might have lost the $\mathrm{HB}$ immune memory but still produce some anti-HBs after one dose of $\mathrm{HB}$ vaccine. To further understand this issue, early immune response were assayed in all the subjects

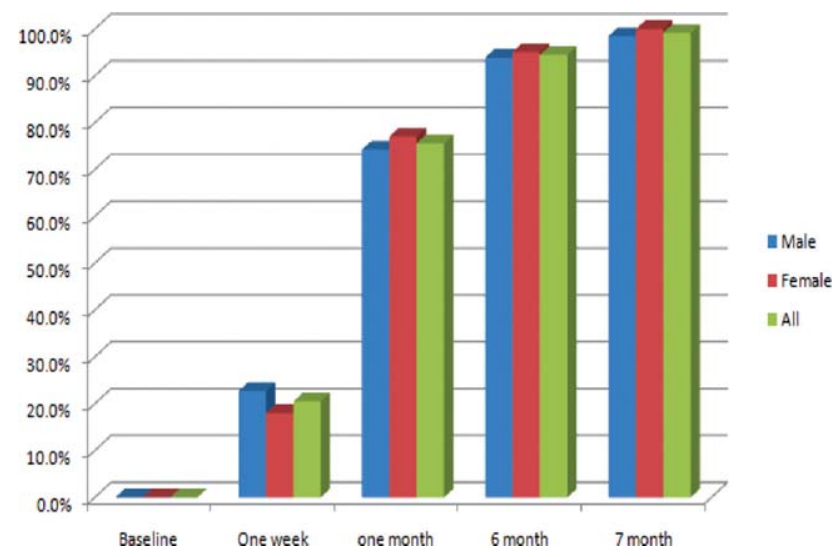

Fig. 2. Seroprotective rates for anti-HBs after booster doses of Hepatitis $\mathrm{B}$ vaccine by gender $(\mathrm{N}=127)$. 
Table 2. Hepatitis B Surface Antigen Antibody (anti-HBs) Titer Responses Among 127 Participants at Different Timepoints

\begin{tabular}{|c|c|c|c|c|c|c|c|c|c|c|c|c|c|c|c|c|c|c|c|c|}
\hline & \multicolumn{20}{|c|}{ Time } \\
\hline & \multicolumn{2}{|c|}{ 7-10 Days } & \multicolumn{6}{|c|}{1 Month } & \multicolumn{6}{|c|}{6 Months } & \multicolumn{6}{|c|}{7 Months } \\
\hline & \multirow[b]{2}{*}{$\mathbf{N}$} & \multirow[b]{2}{*}{$(\%)$} & \multicolumn{2}{|c|}{$<10 \mathrm{mlU} / \mathrm{mL}$} & \multicolumn{2}{|c|}{$\begin{array}{r}10-100 \\
\mathrm{mIU} / \mathrm{mL}\end{array}$} & \multicolumn{2}{|c|}{$\begin{array}{c}\geq 100 \\
\mathrm{mlU} / \mathrm{mL}\end{array}$} & \multicolumn{2}{|c|}{$\begin{array}{c}<10 \\
\mathrm{mIU} / \mathrm{mL}\end{array}$} & \multicolumn{2}{|c|}{$\begin{array}{c}10-100 \\
\mathrm{mIU} / \mathrm{mL}\end{array}$} & \multicolumn{2}{|c|}{$\begin{array}{c}\geq 100 \\
\mathrm{mlU} / \mathrm{mL}\end{array}$} & \multicolumn{2}{|c|}{$\begin{array}{c}<10 \\
\mathrm{mIU} / \mathrm{mL}\end{array}$} & \multicolumn{2}{|c|}{$\begin{array}{c}10-100 \\
\mathrm{mlU} / \mathrm{mL}\end{array}$} & \multicolumn{2}{|c|}{$\begin{array}{c}\geq 100 \\
\mathrm{mIU} / \mathrm{mL}\end{array}$} \\
\hline & & & $\mathbf{N}$ & $(\%)$ & $\mathbf{N}$ & $(\%)$ & $\mathbf{N}$ & $(\%)$ & $\mathbf{N}$ & $(\%)$ & $\mathbf{N}$ & $(\%)$ & $\mathbf{N}$ & $(\%)$ & $\mathbf{N}$ & $(\%)$ & $N$ & $(\%)$ & $\mathbf{N}$ & $(\%)$ \\
\hline$<10 \mathrm{mlU} / \mathrm{mL}$ & 101 & $(79.5)$ & 31 & $(24.4)$ & 36 & (28.3) & 34 & $(26.8)$ & 7 & $(5.5)$ & 28 & $(22.0)$ & 66 & $(52.0)$ & 1 & $(0.8)$ & 4 & (3.1) & 96 & (75.6) \\
\hline $10-100 \mathrm{mIU} / \mathrm{mL}$ & 18 & $(14.2)$ & 0 & $(0.0)$ & 1 & $(0.8)$ & 17 & $(13.4)$ & 0 & $(0.0)$ & 1 & $(0.8)$ & 17 & $(13.4)$ & 0 & $(0.0)$ & 0 & $(0.0)$ & 18 & $(14.2)$ \\
\hline$\geq 100 \mathrm{mlU} / \mathrm{mL}$ & 8 & $(6.3)$ & 0 & $(0.0)$ & 0 & $(0.0)$ & 8 & (6.3) & 0 & $(0.0)$ & 1 & $(0.8)$ & 7 & $(5.5)$ & 0 & $(0.0)$ & 0 & $(0.0)$ & 8 & (6.3) \\
\hline Total & 127 & $(100)$ & 31 & $(24.4)$ & 37 & $(29.1)$ & 59 & (46.5) & 7 & $(5.5)$ & 30 & (23.6) & 90 & (70.9) & 1 & $(0.8)$ & 4 & (3.1) & 122 & $(96.1)$ \\
\hline
\end{tabular}

7-10 days after vaccination. Roughly one-quarter $(24.4 \%)$ of the subjects had nonprotective anti-HBs $(<10 \mathrm{mIU} / \mathrm{mL})$ at $7-10$ days and 1 month after a single dose of $\mathrm{HB}$ vaccine.

All the study subjects were grouped according to their anti-HBs titer 7-10 days after 1 dose of $\mathrm{HB}$ vaccine, namely, those $<10 \mathrm{mIU} / \mathrm{mL}$ (group A), those between 10-100 $\mathrm{mIU} / \mathrm{mL}$ (group B), and those $\geq 100$ $\mathrm{mIU} / \mathrm{mL}$ (group $\mathrm{C}$ ) as shown in Table 3. One month after $\mathrm{HB}$ vaccination, essentially all subjects $(25 / 26)$ in group $B$ and $C$ had anti-HBs titers more than 100 $\mathrm{mIU} / \mathrm{mL}$, which was only seen in 34 out of 101 subjects in group A (Table 2). Moreover, subjects in groups B and C had anti-HBs GMT 20- to 30-fold higher than that of group A after 1 month; this striking difference persisted to 6 months but was not seen at 7 months after three doses of $\mathrm{HB}$ vaccine. Of note was that groups $\mathrm{B}$ and $\mathrm{C}$ were comparable throughout the study in terms of their anti-HBs titers.

\section{Discussion}

To the best of our knowledge, this is the first prospective study administering three doses of $\mathrm{HB}$ vaccines with a 7-month follow-up for youths who had previously received at least three doses of neonatal HB vaccines. The participants in this study were the oldest cohort studied following the launch of the Taiwanese neonatal $\mathrm{HB}$ immunization program with a mean age of around 20 years. The study will shed light on the kinetics of the early booster response, and this will help us understand the length of protection after primary immunization of $\mathrm{HB}$ vaccine in infancy.

We showed a high success rate $(99.2 \%)$ following the three doses of $\mathrm{HB}$ vaccines among adolescents and young adults aged around 20 years. Our findings were similar to those from central Taiwan in a younger aged cohort of $12-15$ years $(97.3 \%) .^{10}$

Loss of $\mathrm{HB}$ vaccine immune memory could be easily detected by low anti-HBs $(<10 \mathrm{mIU} / \mathrm{mL})$ production following one dose of booster $\mathrm{HB}$ vaccination. Defining the presence of $\mathrm{HB}$ vaccine immune memory could be problematic because production of higher anti-HBs $(>10 \mathrm{mIU} / \mathrm{mL}) 1$ month after booster vaccination may result from primary immune response or anamnestic response. Most studies gave a booster dose of the vaccine to seronegative (anti-HBs $<10 \mathrm{mIU} /$ $\mathrm{mL}$ ) subjects who had completed the $\mathrm{HB}$ vaccination in infancy. Blood samples were taken before and 3-4 weeks after vaccination. If the postvaccination serum remained seronegative, this subject was considered to have lost immune memory to $\mathrm{HB}$ vaccine antigens.

Table 3. Geometric Mean Titers (GMT) at 1, 6, and 7 Months Categorized by Hepatitis B Surface Antigen Antibody (antiHBs) Titers at 7-10 Days After Booster

\begin{tabular}{|c|c|c|c|c|}
\hline Group & $\begin{array}{c}\text { A } \\
\mathrm{N}=101\end{array}$ & $\begin{array}{c}B \\
N=18\end{array}$ & $\begin{array}{c}C \\
N=8\end{array}$ & \\
\hline Anti-HBs at 7-10 days after 1 dose of HB vaccination & $<10 \mathrm{mlU} / \mathrm{mL}$ & $10-100 \mathrm{mlU} / \mathrm{mL}$ & $\geq 100 \mathrm{mlU} / \mathrm{mL}$ & $P$ Value* \\
\hline GMT at 1 month $(95 \% \mathrm{Cl})$ [Range] & $\begin{array}{c}22.4 \\
(12.6 \sim 40.2) \\
{[0.1 \text { to } 907.5]}\end{array}$ & $\begin{array}{c}467.9 \\
(306.5 \sim 714.4) \\
{[33.1 \text { to } 1000]}\end{array}$ & $\begin{array}{c}637.2 \\
(328.2 \sim 1237.0) \\
{[104.4 \text { to } 1000]}\end{array}$ & $<0.0001$ \\
\hline GMT at 6 months & $\begin{array}{c}159.1 \\
(112.3 \sim 225.5) \\
{[0.1 \text { to } 1000]}\end{array}$ & $\begin{array}{c}548.8 \\
(373.8 \sim 805.7) \\
{[95.3 \text { to } 1000]}\end{array}$ & $\begin{array}{c}648.4 \\
(249.7 \sim 1684.0) \\
{[38.7 \text { to } 1000]}\end{array}$ & 0.0021 \\
\hline GMT at 7 months & $\begin{array}{c}706.0 \\
(598.4 \sim 832.9) \\
{[7 \text { to } 1000]}\end{array}$ & $\begin{array}{c}971.0 \\
(912.6 \sim 1033.0) \\
{[588.8 \text { to } 1000]}\end{array}$ & $\begin{array}{c}807.3 \\
(526.6 \sim 1238.0) \\
{[232.3 \text { to } 1000]}\end{array}$ & 0.26 \\
\hline
\end{tabular}

*ANOVA test. Figures in parentheses are 95\% confidence interval. Figures in brackets are ranges. 
However, there was a group of subjects who mounted low-level anti-HBs (10-100 mIU/mL) responses after one dose of the $\mathrm{HB}$ vaccine. The interpretation for these subjects was less clear. They might manifest an anamnestic response or have lost immune memory and mounted a primary response. This study aimed to clarify this issue by studying early responses to $\mathrm{HB}$ vaccines. Our results demonstrated that early responders (anti-HBs $\geq 10 \mathrm{mIU} / \mathrm{mL}$ at $7-10$ days after vaccination; groups $\mathrm{B}$ and $\mathrm{C}$ ) eventually developed a significantly higher anti-HBs GMT at 1 month and 6 months compared with the nonearly responders (group A). Almost all early responders had high anti-HBs titer $(\geq 100 \mathrm{mIU} / \mathrm{mL})$ after 1 month. This supported the notion that early responders maintained immune memory and thus would have more robust immune responses to $\mathrm{HB}$ vaccine compared with the nonearly responders. We also found that the levels of the early response were not critical. Those with early anti-HBs between 10 and $100 \mathrm{mIU} / \mathrm{mL}$ (group B) and anti-HBs $\geq 100 \mathrm{mIU} / \mathrm{mL}$ (group C) behaved similarly in the subsequent anti-HBs responses. Hence, we believe that a conversion of anti-HBs from $<10 \mathrm{mIU} / \mathrm{mL}$ to $>10$ $\mathrm{mIU} / \mathrm{mL}$ 7-10 days after one dose of the $\mathrm{HB}$ vaccine booster could be defined as the presence of immune memory.

Participants with an early booster response had titers up to 20 times higher than those who could not mount an early response after 1 month. These findings suggest that when immune memory was present, anti-HBs responses could be induced as early as 1 week following a booster and such responders are likely to have protective titers after a single dose and may not need further doses. However, subjects who do not mount an anamnestic response might still be able to mount a protective response to infection.

The nonresponding rates to plasma-derived $\mathrm{HB}$ vaccines have been estimated to be less than $10 \%$ according to previous studies. ${ }^{7,19}$ Some of those who had a slow or no response to the second course of $\mathrm{HB}$ vaccines might be nonresponders but they are few. In our study, 94.5\% subjects had seroconversion after the second dose at second course of $\mathrm{HB}$ vaccinations and almost all except one did after three doses of revaccination. With regard to the kinetics of anti-HBs titers, there was a total of 17 cases (13.4\%) with unsustained anti-HBs response between doses of $\mathrm{HB}$ vaccines in our study. Among them, 15 cases had decreased anti$\mathrm{HBs}$ titer at 6 months, just before the third dose of $\mathrm{HB}$ vaccine. Another two cases had a decrease in antiHBs titer at 7 months, 1 month after the third dose of $\mathrm{HB}$ vaccine.
In previous studies, females had a stronger immunogenic response to $\mathrm{HB}$ vaccine with higher anti-HBs seropositivity and a reduced chance for $\mathrm{HB}$ infection. ${ }^{20-22}$ However, no significant gender difference for $\mathrm{HB}$ vaccination response was found in our study or in a recent study in central Taiwan. ${ }^{10}$ We also did not detect significant differences in anti-HBs titers during four follow-up periods with respect to age, family history of $\mathrm{HB}$ virus carriage, blood type, or BMI (see Table 1). However, it is interesting to note that out of eight participants with blood type $\mathrm{AB}$ none had an early booster response. Although the sample size was small, further studies to explore the relationship between blood type and booster response may be warranted.

There remain persistent arguments about the role of T-cell immune memory associated with $\mathrm{HB}$ vaccines. We have estimated that $10 \%$ to $26.5 \%$ of fully vaccinated adolescents may have lost their $\mathrm{HB}$ vaccine-conferred booster response using an enzyme-linked immunospot assay to estimate memory T-cell immune response, together with $\mathrm{HBsAg-specific} \mathrm{IFN-} \gamma$ - or IL5-secreting peripheral blood mononuclear cells assays. ${ }^{7}$ In Thailand, 87 high-risk individuals who had received a complete course of recombinant $\mathrm{HB}$ vaccine 18-20 years earlier were investigated for their $\mathrm{HB}$ virus immune memory. Overall, $58.6 \%$ of participants were seropositive for humoral immunity and 50.6\% were positive using the enzyme-linked immunospot assay for cellular immunity. It was concluded that a second booster dose should be considered, especially in highrisk groups. ${ }^{23}$ In the present study, only $20.5 \%$ of the previously vaccinated subjects had an early booster response; they may be potentially vulnerable to $\mathrm{HB}$ virus infection.

A difference between immune responses to plasmaderived vaccines and recombinant vaccines has been suggested before. Floreani et al. ${ }^{24}$ found a faster decay rate of anti-HBs with recombinant vaccines. Kao et al. ${ }^{10}$ studied students at a junior middle school of a rural township in central-southern Taiwan. After a booster dose the percentage of anamnestic responses increased with a trend toward the younger cohort born after $1992(P<0.001)$. The recombinant vaccine showed fast disappearance rates $(62.7 \%)$ of the surface antibody against HB 12-15 years after vaccination, but provided better anamnestic responses after a booster dose. However, the cohort effects of these differences could not be excluded. In our study all the study subjects received the same plasma-derived $\mathrm{HB}$ vaccines and completed $\mathrm{HB}$ vaccination during their infancy. Moreover, recombinant $\mathrm{HB}$ vaccines were used in the 
second course of vaccinations in this study. Because of this homogeneity, this study could not answer if there is any association between response to the second course of $\mathrm{HB}$ vaccine and different dosage and types of $\mathrm{HB}$ vaccines at birth. Only two subjects received hepatitis B immunoglobulin (HBIG) at birth. Hence, it was not feasible to examine the relationship between HBIG and subsequent long-term immunity as suggested before. $^{25}$

Our study implies two possible strategies for youth who received complete $\mathrm{HB}$ vaccination in neonatal or infant period but are seronegative for $\mathrm{HB}$ seromarkers. The first strategy is to check the anti-HBs 1 week after the first booster dose. If there is immune memory based on early anti-HBs seroconversion, no further vaccine doses would be needed. If negative, however, two subsequent doses are needed to ensure seroprotection in more than $90 \%$ of vaccinees. A second strategy is to give at least two doses ( 1 month apart) to ensure the seropositive rate is higher than $90 \%$ without further testing of anti-HBs. A response rate higher than $90 \%$ is probably sufficient to minimize the risk of acquisition in a highly immunized population with good herd immunity. Both strategies need substantial resources and efforts. The cost-effectiveness of these two strategies warrants further evaluation. In the meantime, surveillance of acute HB should continue to see if further vaccinations are needed. ${ }^{26}$

Some limitations of this study should be noted. First, there was no study arm to examine the decay in GMT over time with a single dose of $\mathrm{HB}$ vaccine. In addition, our study was not designed to detect natural seroconversion from seronegative to seropositive among adolescents and young adults who had completed their neonatal HB immunization. Finally, we did not address the possible presence of T-cell memory among the seronegative patients.

In conclusion, at least one-quarter of $\mathrm{HB}$ vaccinees have lost their immune memory to the $\mathrm{HB}$ vaccine when entering college. Immune memory to $\mathrm{HB}$ vaccine could be identified by early seroconversion, which was present in only $20 \%$ of vaccinees in this study. To ensure higher than $90 \%$ anti-HBs seroconversion rates, at least two doses of $\mathrm{HB}$ booster are recommended for at-risk youths who received complete $\mathrm{HB}$ vaccinations in neonatal or infant periods but are seronegative for $\mathrm{HBsAg}$, anti-HBc, and anti-HBs in adolescence.

Acknowledgment: We thank the Taiwan Center for Disease Control government for data linkage; National Taiwan University, and Michigan State University for administrative help; and Ms. H.F. Hu, Ms. Y.S. Lin, and Mr. Huang for assistance.

\section{References}

1. Chang MH, Chen CJ, Lai MS, Hsu HM, Wu TC, Kong MS, et al. Universal hepatitis B vaccination in Taiwan and the incidence of hepatocellular carcinoma in children. Taiwan Childhood Hepatoma Study Group. N Engl J Med 1997;336:1855-1859.

2. Kao JH, Hsu HM, Shau WY, Chang MH, Chen DS. Universal hepatitis $\mathrm{B}$ vaccination and the decreased mortality from fulminant hepatitis in infants in Taiwan. J Pediatr 2001;139:349-352.

3. Hsu HM, Chen DS, Chuang CH, Lu JC, Jwo DM, Lee CC, et al. Efficacy of a mass hepatitis B vaccination program in Taiwan. Studies on 3464 infants of hepatitis B surface antigen-carrier mothers. JAMA 1988;260:2231-2235.

4. Chien YC, Jan CF, Kuo HS, Chen CJ. Nationwide hepatitis B vaccination program in Taiwan: effectiveness in the 20 years after it was launched. Epidemiol Rev 2006;28:126-135.

5. Tsen YJ, Chang MH, Hsu HY, Lee CY, Sung JL, Chen DS. Seroprevalence of hepatitis B virus infection in children in Taipei, 1989: five years after a mass hepatitis B vaccination program. J Med Virol 1991; 34:96-99.

6. Chen HL, Chang MH, Ni YH, Hsu HY, Lee PI, Lee CY, et al. Seroepidemiology of hepatitis B virus infection in children: ten years of mass vaccination in Taiwan. JAMA 1996;276:906-908.

7. Lu CY, Ni YH, Chiang BL, Chen PJ, Chang MH, Chang LY, et al. Humoral and cellular immune responses to a hepatitis $\mathrm{B}$ vaccine booster $15-18$ years after neonatal immunization. J Infect Dis 2008; 197:1419-1426.

8. Lee PI, Lee CY, Huang LM, Chang MH. Long-term efficacy of recombinant hepatitis $B$ vaccine and risk of natural infection in infants born to mothers with hepatitis B e antigen. J Pediatr 1995;126: 716-721.

9. Lin YC, Chang MH, Ni YH, Hsu HY, Chen DS. Long-term immunogenicity and efficacy of universal hepatitis B virus vaccination in Taiwan. J Infect Dis 2003;187:134-138.

10. Kao JT, Wang JH, Hung CH, Yen YH, Hung SF, Hu TH, et al. Longterm efficacy of plasma-derived and recombinant hepatitis $\mathrm{B}$ vaccines in a rural township of Central Taiwan. Vaccine 2009;27:1858-1862.

11. Ni YH, Huang LM, Chang MH, Yen CJ, Lu CY, You SL, et al. Two decades of universal hepatitis $\mathrm{B}$ vaccination in Taiwan: impact and implication for future strategies. Gastroenterology 2007;132: 1287-1293.

12. Chang HC, Yen CJ, Lee YC, Chiu TY, Jan CF. Seroprevalence of hepatitis B viral markers among freshmen - 20 years after mass hepatitis B vaccination program in Taiwan. J Formos Med Assoc 2007;106: 513-519.

13. Boot HJ, van der Waaij LA, Schirm J, Kallenberg CG, van Steenbergen J, Wolters B. Acute hepatitis B in a healthcare worker: a case report of genuine vaccination failure. J Hepatol 2009;50:426-431.

14. Lee GC, Hwang LY, Beasley RP, Chen SH, Lee TY. Immunogenicity of hepatitis B virus vaccine in healthy Chinese neonates. J Infect Dis 1983;148:526-529.

15. Zuckerman JN. Protective efficacy, immunotherapeutic potential, and safety of hepatitis B vaccines. J Med Virol 2006;78:169-177.

16. Lu CY, Chiang BL, Chi WK, Chang MH, Ni YH, Hsu HM, et al. Waning immunity to plasma-derived hepatitis $\mathrm{B}$ vaccine and the need for boosters 15 years after neonatal vaccination. Hepatology 2004;40: 1415-1420.

17. Samandari T, Fiore AE, Negus S, Williams JL, Kuhnert W, McMahon $\mathrm{BJ}$, et al. Differences in response to a hepatitis $\mathrm{B}$ vaccine booster dose among Alaskan children and adolescents vaccinated during infancy. Pediatrics 2007;120:e373-382.

18. Kirkman TW. 1996. Statistics to use. http://www.physics.csbsju.edu/ stats Accessed 20 April 2009.

19. Zuckerman JN. Protective efficacy, immunotherapeutic potential, and safety of hepatitis B vaccines. J Med Virol 2006;78:169-177. 
20. Dentico P, Buongiorno R, Volpe A, Zavoianni A, Pastore G, Schiraldi O. Long term immunogenicity safety and efficacy of a recombinant hepatitis B vaccine in healthy adults. Eur J Epidemiol 1992;8:650-655.

21. Fang JW, Lai CL, Chung HT, Wu PC, Lau JY. Female children respond to recombinant hepatitis $\mathrm{B}$ vaccine with a higher titer. J Trop Pediatr 1994;40:104-107.

22. Chen CC, Yen CH, Wu WY, Hu SW, Chen SC, Bell WR, et al. Epidemiology of hepatitis B virus infection among young adults in Taiwan, China after public vaccination program. Chinese Med J 2007; 120:1155-1158.

23. Chinchai T, Chirathaworn C, Praianantathavorn, Theamboonlers A, Hutagalung Y, Bock $\mathrm{PH}$, et al. Long-term humoral and cellular immune response to hepatitis B vaccine in high-risk children 18-20 years after neonatal immunization. Viral Immunol 2009;22:125-130.

24. Floreani A, Baldo V, Cristofoletti M, Renzulli G, Valeri A, Zanetti C, et al. Long-term persistence of surface antibody against hepatitis $\mathrm{B}$ after vaccination against $\mathrm{HBV}$ : an 18-year experience in health care workers. Vaccine 2004;22:607-610.

25. Boxall EH, A Sira J, El-Shuhkri N, Kelly DA. Long-term persistence of immunity to hepatitis B after vaccination during infancy in a country where endemicity is low. J Infect Dis 2004;190:1264-1269.

26. Kao JH, Chen DS. Hepatitis B vaccination: to boost or not to boost? Lancet 2005;366:1337-1338. 